\title{
Formação do Professor Universitário na Área de Turismo no Brasil
}

\section{Nizamar Aparecida de Oliveira}

Mestre em Hospitalidade pela Universidade Anhembi Morumbi. Pós-graduada em Metodologias e Gestão para Educação a Distância pela Anhanguera Educacional S.A. Pós-Graduada em Didática do Ensino Superior pelo Centro Hispano Brasileiro de Cultura. Graduada em Gestão em Negócios Securitários pelo Centro Hispano Brasileiro de Cultura - UNIBERO. Graduada em Turismo pelo Centro Hispano Brasileiro de Cultura - UNIBERO. Docente nos cursos de graduação e pósgraduação. Coordenadora dos Cursos de Turismo e Gestão em Negócios Securitários. Atualmente ministra aulas no curso de Turismo União das Faculdades dos Grandes Lagos - Unilago, Brasil; nizamar@uol.com.br

Recibido: 13 de enero, 2015 - Aceptado: 11 de setiembre, 2015 - Corregido: 22 de octubre, 2015

\section{RESUMO}

Qual o perfil do estudante de Turismo na atualidade? O professor universitário está capacitado para os novos desafios educacionais? É importante que o professor atue no mercado? Como lidar com o professor que vê, na docência apenas uma renda complementar? Este artigo pretende analisar a formação do professor universitário no curso de Turismo, mediante as mudanças provocadas pela tecnologia. O trabalho terá como metodologia, a experiência de sala de aula, vivenciada pela autora, bem como a coordenação do curso de Turismo em um centro universitário. Como referencial teórico serão utilizados os autores Almeida (2012) que aborda a formação do professor universitário; Camargo (2003), no quesito Hospitalidade; Guimarães e Borges (2008) que analisam as ferramentas tecnológicas e o turismo e Molina (2013) que dedicou um livro ao pós-turismo. Como resultado, uma reflexão para todos os professores e coordenadores de curso sobre uma reavaliação de suas práticas profissionais em sala de aula.

Palavras-chave: Capacitação, Educação, Hospitalidade, Brasil.

\section{ABSTRACT \\ Formation of University Professor in the area of tourism in Brazil}

What Tourism student profile today? The professor is qualified for the new educational challenges? It is important that the teacher acts in the market? How to deal with the teacher who sees in teaching only a supplementary income? This article analyzes the formation of the university teacher in the course of Tourism, through the changes caused by technology. Work will methodology, classroom experience, experienced by the author, as well as coordination of the Tourism course at a university center. Theoretical framework the authors Almeida will be used (2012) which deals with the formation of the university teacher; Camargo (2003), in the category

Formato de citación según APA

Aparecida de Oliveira, N. (2016). Formação do Professor Universitário na Área de Turismo no Brasil. Revista Espiga, Vol XV, (31), 1-11. 
Hospitality; Guimarães and Borges (2008) analyzing technological tools and tourism and Molina (2013), a book dedicated to post-tourism. As a result, a reflection for all teachers and course coordinators on a reassessment of their professional practices in the classroom.

Key words: Training, Education, Hospitality, Brazil.

\section{INTRODUÇÃO}

De acordo com uma pesquisa realizada no sítio do Ministério da Educação ${ }^{1}$, o Brasil possui mais de 600 Instituições de Ensino Superior (IES) com o curso de Turismo. Na pesquisa, foi possível constatar uma segmentação e variação nas ofertas. Algumas IES, oferecem bacharelados e tecnólogos de Turismo. Outras, cursos como Turismo e Hotelaria, Turismo e Hospitalidade, Turismo Receptivo, Turismo e Meio Ambiente, Marketing Turístico, Turismo de Eventos. Predominando, entretanto o curso de Bacharelado em Turismo.

Não basta haver oferta e demanda destes cursos. Se faz necessário que as IES tenham uma preocupação com a composição do corpo docente. Professores comprometidos com a docência, responsáveis, cumpridores de seus deveres.

Não raro, no papel de coordenadora, recebo alunos comentando de professor que não tem didática. Embora o aluno não saiba definir a verdadeira essência desta palavra, ele sabe discernir que o professor não consegue transmitir o conteúdo de forma adequada.

O presente trabalho surgiu após a apresentação de um simpósio chamado "La formación de profesionales de turismo: Desafíos y Perspectivas", com a apresentação do tema: Formação de Professores Universitários na área de Turismo no Brasil na Universidade Técnica de Cotopaxi Ecuador. Vivenciar um Congresso Internacional em que o discurso dos professores são os mesmos em várias universidades dos vários países da América Latina, provoca uma reflexão e clama por uma mudança urgente.

1. http://emec.mec.gov.br/
Para compreender melhor o tema, o trabalho está dividido em segmentos, conforme apresentado no congresso. Ficando desta forma: Tópico 1. O Turismo em números; 2. O professor de Turismo; 3. Novas tecnologias e o Turismo; 4. O novo turista; 5. Oportunidades e 6. O novo profissional de Turismo.

Embora com fundamentação em livros relacionados aos tópicos apresentados no parágrafo acima, o trabalho se baseará essencialmente na experiência de docente nos cursos de Turismo, Eventos, Hotelaria e coordenadora do curso de Turismo.

A fundamentação teórica será baseada nos autores Almeida (2012) que, segundo a autora "a qualificação profissional dos professores tem peso determinante na sua atuação e, consequentemente, na qualidade do ensino ministrado" (p.68); Camargo (2003), renomado autor nas da hospitalidade, que tem a frequente preocupação com o dom da dádiva e a tríade da hospitalidade (dar, receber e retribuir) e os tempos da hospitalidade (receber, hospedar, alimentar e entreter), nos apontando a permanente necessidade do docente e dos discentes do Turismo trabalharem esses fatores; Guimarães e Borges (2008) que analisam a atual realidade e as ferramentas tecnológicas como sites, blogs, sistemas eletrônicos de reservas como aliados para o profissional de Turismo Molina (2013) que dedicou um livro ao pós-turismo, ou seja, a ruptura entre o turismo tradicional e as novas características diante deste mundo em permanente transformação, que exige, portanto, um novo profissional, disposto a enfrentar tais desafios.

O Turismo no Brasil não tem muito incentivo na área acadêmica, ainda que o país seja como se costuma dizer "abençoado por Deus e bonito por natureza", parte da composição de Jorge Ben Jor e interpretado por vários cantores. As políticas 
públicas também são mais teóricas que práticas. O Plano Nacional de Turismo que é elaborado por quadriênios, sendo o que se encontra em vigor o de 2013-2016, possui um extenso texto, que pouco podemos constatar na prática.

Por isso, por pouco incentivo à pesquisa, não foi possível encontrar muitos artigos relacionados ao Turismo e a Docência. As pesquisas da autora trouxe apenas Ansarah (s/d) que analisa a relação professor-aluno na construção do conhecimento. Outro artigo publicado por Mesquita, Silva e Ribeiro, analisa o papel do professor de Turismo na formação deste profissional.

\section{O Turismo em números.}

O Brasil tem uma costa marítima de 8000 quilômetros. Possui 17 Estados na costa litorânea, totalizando 2045 praias. Portanto, no imaginário dos turistas, principalmente estrangeiros, o Brasil se concentra no Turismo dos 3 S's (Sand, Sun and Sea) ou seja, a oferta resume-se à areia, sol e mar.

Entretanto, embora tenhamos um litoral extenso e atrativo, o Brasil esconde destinos deslumbrantes com as mais variadas ofertas turísticas como o turismo de aventura, turismo rural, turismo de saúde, turismo de compras, turismo de negócios, ecoturismo, turismo de observação, entre tantos.

O Ministério do Turismo através Programas de Regionalização de Turismo², busca valorizar os destinos com ofertas específicas atraindo assim, não apenas turistas brasileiros como também, de âmbito internacional.

São vários os programas governamentais que, lamentavelmente limitam-se à extensos textos e que não podemos ver na prática. Um excelente exemplo são os Arranjos Produtivos Locais (APL) ${ }^{3}$ que tem o objetivo de valorizar os pequenos produtores de um determinado ponto turístico para que estes se beneficiem através do turismo local.

2. http://www.turismo.gov.br/export/sites/default/turismo/o ministerio/publicacoes/downloads_publicacoes/plano_nacional_2013.pdf
É sabido que, se o autóctone não tiver benefício em relação ao turismo, não terá nenhum interesse em incentivá-lo. Afinal, qual a vantagem em receber um número grande de turistas em determinadas ocasiões, causando transtornos ao morador, como escassez do abastecimento de água, sujeira, transtornos para utilização de modais de transportes públicos, excesso de veículos nas ruas, trânsito caótico, falta de mercadoria para consumo próprio?

Se o autóctone for parte integrante desse processo, ou seja, o restaurante, o meio de hospedagem, o meio de transporte, o artesanato e a maioria da forma de consumo do turista for gerada pelo residente, este terá interesse em atrair turistas para sua região, pois sabe que terá vantagem financeira.

Os APL's podem ainda compreender não apenas um destino turístico, mas ainda, um circuito. Tomemos por exemplo, o Circuito das Águas Paulista que abrange as cidades de: Águas de Lindóia, Amparo, Holambra, Jaguariúna, Lindóia, Monte Alegre do Sul, Pedreira, Serra Negra e Socorro. Vale ressaltar que as cidades estão citadas em ordem alfabética e não em relação às distâncias ou proximidades.

Estas cidades possuem várias ofertas turísticas como o turismo de aventura, turismo de saúde, artesanato, turismo rural e uma gastronomia diversificada e muito rica. Contudo, nem todas cidades possuem alternativas de hospedagem ou até mesmo uma gastronomia diferenciada. Desta forma, o turista que visita, por exemplo, a cidade de Pedreira para a aquisição de peças de porcelana, pode sentir-se atraído por hospedar-se em uma cidade com mais atrativos noturnos. Ou ainda, desfrutar de um delicioso café da manhã em um hotel fazenda.

Contudo, uma viagem a estas cidades pode comprovar que não há preparo por parte dos

3. http://www.turismo.gov.br/export/sites/default/turismo/o ministerio/publicacoes/downloads publicacoes/ TURISMO_COMO_INSTRUMENTO_DE_DESENVOLVIMENTO_REGIONAL_ESTUDO_DE_ARRANJOS PRODUTIVTOS LOCAIS XAPLSX NO SETOR DE TURISMO.pdf 
moradores. A hospitalidade deixa muito a desejar, lojistas não sabem dar informação alguma. Em Serra Negra, com os alunos, fomos muito mal atendidos em um restaurante que nos aguardava para um jantar que eram sobras do almoço, tendo como resultado, alunos passando mal no decorrer da noite. Socorro é uma cidade modelo em turismo de aventura para portadores de necessidades especiais. Mas, um parque que, embora tenha grande preocupação com a segurança na prática das atividades, não tinha o número suficiente de profissionais para atender os alunos em uma simples tirolesa. Alegaram que estavam em reunião, atrasando assim, toda programação do dia.

Em uma outra viagem, Águas de Lindóia também nos expôs a riscos desnecessários, em um restaurante que possui práticas como tirolesa, arvorismo e cavalgada, uma aluna sofreu uma queda de cavalo e não teve atendimento nenhum por parte do local. No arvorismo e na tirolesa crianças nos preparavam para as práticas e não nos foi oferecido nenhum Equipamento de Proteção Individual (EPI), além de uma cadeirinha que o instrutor insistia em dizer que não podia ficar muito presa à perna para não machucar. Capacetes e luvas não faziam parte dos EPI's. O passeio de quadriciclo era monitorado por um menino com não mais de 14 anos, pilotando uma moto. Ou seja, completamente fora dos padrões legais de segurança.

Portanto, torna-se fundamental que, através de Políticas Públicas e Privadas, haja uma interação e uma divulgação dos destinos, não apenas atraindo turistas para estes locais como ainda, por um período maior de permanência. Contudo, é muito importante que os destinos estejam preparados para receberem os turistas dentro de um padrão de segurança e hospitalidade.

Estes destinos servem apenas como um breve exemplo, pois temos vários locais com circuitos das mais diversas ofertas turísticas.

\section{O Professor de Turismo}

O aluno desavisado de Turismo vislumbra um curso com muitas viagens, preferencialmente custeadas pela IES, e nada de aulas teóricas e principalmente com cálculos. E muitos profissionais da educação acreditam que, para serem docentes na área, basta ter viajado o mundo, ou até mesmo ter conhecido poucos pontos turísticos e já estão aptos a adentrarem uma sala de aula.

Outro sério problema que os cursos superiores encontram, é o profissional da área que quer ganhar um dinheiro extra e para tanto, basta assumir algumas aulas em uma universidade e ponto final. Em sala de professores, já ouvi comentários que, sinceramente, se fizessem parte dos cursos que coordeno, estariam convidados a não continuarem. Comentários como: Você sabe qual a diferença entre o professor e o aluno? Quinze minutos. Ou seja, em quinze minutos, esse professor fazia uma rápida leitura da matéria do dia e sentia-se cumpridor de sua missão do ensinar. Ou ainda, um professor que preenchia todos os dados da lista (nesta IES a lista de chamada era diária, sendo ainda o controle de saída do professor) em sala de aula, calmamente. No fim da aula, fazia uma chamada para conferir se de fato esses alunos estavam em sala de aula e fazia um controle pessoal para posteriormente, digitar essas faltas no sistema. Ele contava, cheio de si, que com esse procedimento ganhava em torno de 30 minutos por aula.

Esses fatos têm o propósito de ilustrar como não deve ser um professor. No meu ponto de vista e com base no tempo de docência e coordenação no ensino superior, ouso afirmar que deveria ser imprescindível que todo professor do ensino superior tivesse a formação em didática do ensino superior. Lamentavelmente, a única preocupação dos órgãos relacionados à educação é que o professor tenha uma pós-graduação para estar apto à ministrar aulas no ensino superior ${ }^{4}$. Não raro, professores não sabem lidar com problemas corriqueiros em sala de aula. Alguns fazem uso de seu poder, de forma indevida, como se estivéssemos ainda em uma educação bancária, em que o

4. A LDB n 9394/1996 em seu artigo 66 estabelece: “A preparação para o exercício do magistério superior far-se-á em nível de pós-graduação, prioritariamente em programas de mestrado e doutorado." 
professor é o detentor absoluto do conhecimento e o aluno não possui prévio conhecimento. $\mathrm{Na}$ contramão deste professor, há aquele que quer ser «legal» com os alunos e age como se também fosse um deles e estende a sala de aula à cerveja no fim da aula.

É necessário haver um meio termo, saber dosar, impor limites. Caso contrário, não haverá respeito, cumprimento das obrigações. O primeiro professor, aquele que é autoritário, não tem o respeito do aluno e sim o temor. Já o segundo, há um grande desrespeito, pois o aluno precisa sim, conhecer limites.

Comungo com Almeida (2012) que afirma:

Os processos de "preparação do docente" para o ensino superior, segundo estabelecido na $\operatorname{LDB}^{5} \mathrm{n}^{\circ}$ 9.394/1996, são desenvolvidos nos cursos de pósgraduação stricto sensu, nos quais, como sabemos, os objetivos centrais são a pesquisa e a produção conhecimento. Os aspectos relativos à preparação pedagógica para o ensino raramente são parte desses cursos, em que pesam alguns avanços importantes, como a disposição de alguns cursos de pós-graduação stricto sensu de incluir nos seus currículos a disciplina de Metodologia do Ensino Superior e a criação do estágio de docência, iniciado pela Universidade de São Paulo (USP) em 1992 e instituído pela Coordenação de Aperfeiçoamento de Pessoal de Nível Superior (Capes) como obrigatório a todos os seus bolsistas a partir de 1999. (Almeida, 2012, p. 63-64)

No parágrafo seguinte, a autora nos lembra que o docente, embora tenha formação de pós-graduação stricto sensu, com experiência profissional, além de muitos anos de estudos em sua área de formação, em sua maioria estão despreparados para lidar com o processo de ensino-aprendizagem, que são responsáveis quando adentram na sala de aula.

O professor não pode ignorar que o aluno também tem conhecimento prévio. Quando falamos de turismo, muitos conhecem destinos nunca

5. LDB - Lei de Diretrizes e Bases da Educação Nacional (grifo meu) visitados por este. Surge então, uma situação delicada em sala de aula. $\mathrm{O}$ aluno que neste momento agir de forma arrogante, no intuito de menosprezar o docente por este não conhecer lugares, deve se posicionar de forma tranquila porém pontual, mostrando ao aluno que deve ser respeitado e conhecer destinos a serem estudados não o coloca em posição privilegiada. Salvo se este aluno demonstrar que tem pleno conhecimento no que concerne ao campo de estudo da disciplina ministrada, o que é incomum. O aluno deve entender que o professor merece respeito e ele está na condição de discente, portanto, sujeito às regras da IES e da sala de aula. Conhecer um local não implica em conhecimento técnico e teórico, o que o professor tem, por isso está nessa posição.

A sala de aula hoje, devido aos incentivos proporcionados como o Financiamento Estudantil (FIES), o Programa Universidade para Todos (Prouni) para as instituições privadas e os sistemas de cotas para instituições públicas, trouxe à sala de aula uma diversidade de alunos. Assim, em uma sala, teremos as Gerações X, Y e Z convivendo, nem sempre pacificamente. Enquanto alguns alunos possuem uma incrível desenvoltura com as ferramentas tecnológicas, outros apresentam uma dificuldade muito grande.

Se o professor tiver dificuldade com essas ferramentas, como ele poderá auxiliar e até mesmo incentivar o aluno a fazer uso destas? $\mathrm{O}$ aluno logo perceberá a relutância do professor e fará disso um forte argumento no devido momento.

Desta forma, o docente deve se atualizar permanentemente, não há uma aula igual à outra, porque não há turmas iguais. Tudo é dinâmico, globalizado, as informações chegam em tempo real. Não podemos subestimar nada disso. A capacitação deve ser constante.

Mesquita, Silva e Ribeiro (2009) em sua pesquisa, realizada em uma IES com a finalidade de dar suporte ao Projeto Pedagógico, uma pergunta aos alunos referia-se ao professor, se ele preparava aula com antecedência. De um total de 42 questionários, as respostas foram:

A título de exemplo, escolheu-se a variável "Preparo para a aula" (que responde a pergunta: 
"Você considera que os professores preparam antecipadamente as suas aulas?") utilizada no questionário discente. Como todas as outras variáveis, ela foi mensurada no nível ordinal, utilizando as seguintes categorias: "sempre", "a maioria das vezes", "metade das vezes", "poucas vezes", "nenhuma vez". Foi acrescentada mais uma categoria (N.R.) para contabilizar as poucas questões "não respondidas". O resultado final da tabulação dessa variável resultou em nove votos para a categoria "sempre", 31 votos para a categoria "a maioria das vezes" e dois votos para a categoria "metade das vezes". As categorias "poucas vezes" e "nenhuma vez" não receberam votos. (Mesquita, Silva e Ribeiro, 2009, p.50)

Os autores apontam ainda, na pesquisa, que os professores apresentam clareza na exposição das aulas, são organizados e transmitem informações adequadas. Eles afirmam que os discentes que avaliaram os professores são muito críticos e dizem que algumas vezes os docentes transmitem a eles sentimentos desagradáveis deixando transparecer fraqueza no dia-a-dia.

Apesar de poucos pontos fracos, em sua maioria, os professores são bem avaliados pelos discentes. Lamentavelmente, nem todas IES têm a mesma preocupação, ou seja, ter um curso com coordenador, professores e alunos alinhados e com o mesmo intuito, ou seja, a formação do profissional de turismo diante de um mercado em permanente transformação.

\section{Novas tecnologias e o turismo}

Enquanto escrevo este artigo, estou rodeada de livros para pesquisar. Mas, não apenas eles. Busco material em meu HD externo que possui um segundo notebook, praticamente. Estou ain$\mathrm{da}$, com redes sociais abertas, lendo e-mails, interagindo e fazendo pesquisas em diversos sítios, tudo isso em meu fiel companheiro, o notebook.

Não é um privilégio meu, todos internautas fazem isso diuturnamente. Desta forma, é correto afirmar que, se o turista faz uso das ferramentas tecnológicas para programar suas próximas viagens, todo o trade turístico se beneficia com tais ferramentas. Seria, no mínimo ingênuo negar as vantagens da tecnologia neste setor.

Guimarães e Borges (2008) dedicam um livro para a internet e negócios do turismo, dando uma grande contribuição ao setor e, principalmente para a academia. Nesta obra, os autores avaliam as novas tecnologias e negócios do turismo. As agências de viagens a princípio viram a internet como uma ameaça devido a desintermediação dos negócios. Esse risco existe, mas as agências fazem da tecnologia sua aliada, como afirmam os autores:

Apesar de trazer uma grande quantidade de informações, a internet não tem a garantia da confiabilidade [...]. A agência de viagens pode funcionar como um "filtro" das informações confiáveis e seguras. Fazendo isso, as agências de viagens endossam determinados fornecedores de serviços turísticos na rede, podendo legitimamente cobrar por isso. Como um resultado colateral, as agências têm condições de ampliar sua rede de parceiros e produtos disponíveis. (Guimaraes e Borges, 2008, p. 10)

Podemos, como lembram os autores acima, divulgar eventos em escala planetária. Além da funcionalidade pois as inscrições e pagamentos podem ser feitos de qualquer parte, sem a necessidade de locomoção do interessado, evitando filas. Esses eventos podem ocorrer presencialmente ou ainda, de forma virtual. Com uma senha, as pessoas podem participar do evento a distância e com um custo menor. Presenciamos assim, a quebra total de fronteiras, pois um tema que é de interesse, mas a pessoa não pode participar no local, estará até mesmo do outro lado do planeta participando de forma síncrona ou assíncrona.

Meios de hospedagem também fazem uso da internet não apenas para divulgar, como também para fazer reservas. Os hotéis proporcionam ainda, a possibilidade dos hóspedes de participarem de tele e videoconferência, além de escritórios virtuais, fornecendo acesso à internet nos quartos.

Podemos notar na maioria dos restaurantes, que os garçons portam um palmtop para fazerem os pedidos. Assim, o pedido é enviado em tempo real para a cozinha. 
Ainda analisando o trade turístico, temos as atrações turísticas em que os ingressos podem ser comprados antecipadamente, evitando filas, esperas, desconforto, proporcionando ao turista maior tempo livre para outros passeios.

Finalmente, os modais, principalmente o transporte aéreo, que foi o primeiro sistema informatizado a operar em tempo real para reservar passagens (Guimarães e Borges, 2008) O sistema de reserva e compra de bilhetes aéreos maximiza a utilização de assentos, como podemos constatar nos leilões na internet, que se não fosse desta forma, não se captaria essa receita.

\section{O Novo turista}

O dinamismo da globalização resultou em um novo turista, aquele que pesquisa, que pensa e planeja sua próxima viagem com a ajuda de indicação de amigos, blogueiros que contam suas aventuras em seus bloggs e sítios de prefeituras das cidades. Portanto, ele não se contentará em, ao buscar uma agência de viagens, que esta lhe ofereça viagens fechadas, sem alternativas. Muito menos, um destino que ele não tenha o menor interesse. O Ministério do Turismo ${ }^{6}$ assim define o novo turista:

É necessário entender, que o turista hoje tem expectativas que vão além da contemplação passiva dos atrativos. Esse novo perfil de turista, ativo e criativo, quer realizar um desejo além de se sentir um ator importante na construção do destino visitado. Este turista, que está cada vez mais autônomo e bem informado, busca envolver os parentes e amigos nesse processo, fazendo com que a viagem não seja somente lazer, mas também uma atitude militante de partilhar o ambiente, a comunidade visitada e a cultura local, vivendo experiências inesquecíveis e obtendo o poder de convencer os próximos a tomarem essa atitude; viajar com inteligência. (Ministério do Turismo)

6. http://www.turismo.gov.br/turismo/programas_acoes_BACKUP_nao_apagar/programas_acoes/regionalizacao_turismo/economia_experiencia.html
A Copa do Mundo de 2014, realizada no Brasil trouxe, um novo olhar para nossa hospitalidade. Várias pesquisas foram realizadas dentre elas, a do sítio "tudo interessante" em que Luciano Hilton elenca 8 hábitos e costumes praticados pelos brasileiros que deveriam ser exportados, na opinião dos gringos ${ }^{7}$. São estes os hábitos: 1. Abraço, 2. Higiene, 3. Almoçar, 4. Atividades Físicas, 5. Carona, 6. Atendimento, 7. O "jeitinho" brasileiro e 8 . A forma como tratamos os estrangeiros. Hilton conclui que os bons costumes nos enobrecem.

Sem dúvida é uma lição de casa que devemos fazer. Muitos reclamam da inospitalidade de alguns países. Em uma ocasião ouvi de uma pessoa natural de Veneza que, em sua cidade, os moradores não gostam dos turistas. Para eles, se fosse possível, o turista deixaria o dinheiro por lá, mas sequer entraria na cidade. Não é de se admirar que essa pessoa seja apaixonada pelo Brasil e residente na cidade de São Paulo, onde se estabeleceu e confessa ser muito feliz e realizada por aqui.

É claro que não podemos negar que o turista nos traz benefícios, gera renda. Mas, o brasileiro "gosta de gente", não nega uma informação, uma ajuda. Somos alegres, prestativos, o que, a princípio pode assustar, mas é justamente isso que encanta o estrangeiro.

\section{Oportunidades}

Como vimos no tópico anterior, o novo turista quer viver novas experiências em suas viagens. É correto então, trabalhar essas oportunidades. Como? Proporcionando essas novas experiências. Molina (2013) afirma que as empresas pós-turísticas buscam idealizar e concretizar as experiências do turista. O autor exemplifica através da gastronomia, em que aliam o prato servido ao serviço como componentes de algo maior; a experiência e ensina:

7. http://www.tudointeressante.com.br/2014/07/8-habitos-ecostumes-brasileiros-que-deveriam-ser-exportados-na-opiniao-dos-gringos.html 
Na prática isso implica que ao cliente não só se oferece um prato e o serviço que o acompanha, mas que a função de alimentar-se e receber um serviço lhe agrega um valor, o de uma experiência: uma diversão ou um entretenimento, uma fantasia que ultrapassa o cumprimento de uma necessidade fisiológica e de segurança.

Os restaurantes não se destinam, portanto, exclusivamente à alimentação, ao serviço e à socialização. Mas, além de tudo isso, propiciam uma experiência visual, auditiva, táctil e estética, todas elas significativas. (Molina, 2013, p.64)

É certo que todo o trade turístico pode vislumbrar oportunidades. Lamentavelmente, muitas pessoas enxergam como ameaças, têm medo do novo, das mudanças. Porém, estamos vivendo um caminho sem volta, em que o mundo está cada vez menor, graças à tecnologia. Não podemos fechar os olhos para essas evidências.

O serviço de restaurantes foi apenas um exemplo, hotéis que oferecem internet para os hóspedes, espaço para reuniões, restaurantes internacionais, concierge ${ }^{8}$, academia, salão de estética, babás e entretenimentos para as crianças, entre outros serviços. Todo o trade turístico pode repensar e aprimorar o atendimento.

As oportunidades surgem constantemente, mas para tanto, é necessário estar sempre atento às mudanças, investir em pesquisas para conhecer o grau de satisfação dos clientes e o nível de expectativa destes.

Novos segmentos turísticos e novos destinos surgem continuamente. Lembrando ainda que,

8. Nos hotéis ou conciergeries o especialista pode ser encontrado normalmente no hall, pronto para satisfazer qualquer necessidade dos clientes. Sua missão é ampla, desde providenciar um táxi, até dispor todos os informes de que os turistas necessitem, não só sobre o próprio local em que está hospedado, mas também sobre a cidade e seus principais espaços turísticos. O Concierge também atua como intermediário na compra de passeios, ele aluga carros, orienta sobre os melhores restaurantes da região, faz as reservas nos que forem selecionados pelos hóspedes, faz ligações para farmácias e floriculturas, entre outras tantas responsabilidades. Fonte: http://www. infoescola.com/profissoes/concierge/ com a facilidade para pagamentos e tarifas diferenciadas atraem um turismo emergente, pessoas que até pouco tempo, não poderiam viajar.

\section{O Novo profissional de turismo}

Mediante toda análise dos tópicos anteriores, é possível afirmar que o novo profissional deve ter um conhecimento amplo, não pode se limitar a conhecimentos superficiais. Lamentavelmente, para se trabalhar no setor, não é necessário ser turismólogo. A Lei n ${ }^{\circ}$ 12591/2012 foi sancionado com dois vetos que favoreceriam e valorizariam muito mais o profissional da área, a saber?

Dois artigos vetados dizem respeito à qualificação e ao diploma do turismólogo. O primeiro exigia que a profissão fosse exercida pelos diplomados em curso superior de bacharelado em turismo ou hotelaria. O terceiro exigia registro em órgão federal competente mediante apresentação de documento comprobatório da conclusão dos cursos de turismo, hotelaria ou similares, ou comprovação do exercício das atividades de turismólogo, e carteira de trabalho expedida pelo Ministério do Trabalho e Emprego. (Panrotas, 2012)

A Lei possui assim, um único artigo, uma vez que o $1^{\circ}, 3^{\circ}$ e $4^{\circ}$ artigos foram vetados e o $5^{\circ}$ apenas determina a data de início desta, 18 de janeiro de 2012.

$\mathrm{O}$ artigo $2^{\circ}$ considera como atividades do turismólogo, conforme segue ${ }^{10}$ :

Art. 2o Consideram-se atividades do Turismólogo:

I - planejar, organizar, dirigir, controlar, gerir e operacionalizar instituições e estabelecimentos ligados ao turismo;

II - coordenar e orientar trabalhos de seleção e classificação de locais e áreas de interesse turístico, visando ao adequado aproveitamento dos

9. http://www.panrotas.com.br/noticia-turismo/politica/ dilma-regulamenta-profissao-de-turismologo--com-vetos_74877.html

10. http://www.planalto.gov.br/ccivil_03/_ato2011-2014/2012/ lei/112591.htm 
recursos naturais e culturais, de acordo com sua natureza geográfica, histórica, artística e cultural, bem como realizar estudos de viabilidade econômica ou técnica;

III - atuar como responsável técnico em empreendimentos que tenham o turismo e o lazer como seu objetivo social ou estatutário;

IV - diagnosticar as potencialidades e as deficiências para o desenvolvimento do turismo nos $\mathrm{Mu}$ nicípios, regiões e Estados da Federação;

$\mathrm{V}$ - formular e implantar prognósticos e proposições para o desenvolvimento do turismo nos Municípios, regiões e Estados da Federação;

VI - criar e implantar roteiros e rotas turísticas;

VII - desenvolver e comercializar novos produtos turísticos;

VIII - analisar estudos relativos a levantamentos socioeconômicos e culturais, na área de turismo ou em outras áreas que tenham influência sobre as atividades e serviços de turismo;

IX - pesquisar, sistematizar, atualizar e divulgar informações sobre a demanda turística;

X - coordenar, orientar e elaborar planos e projetos de marketing turístico; XI - identificar, desenvolver e operacionalizar formas de divulgação dos produtos turísticos existentes;

XII - formular programas e projetos que viabilizem a permanência de turistas nos centros receptivos;

XIII - organizar eventos de âmbito público e privado, em diferentes escalas e tipologias;

XIV - planejar, organizar, controlar, implantar, gerir e operacionalizar empresas turísticas de todas as esferas, em conjunto com outros profissionais afins, como agências de viagens e turismo, transportadoras e terminais turísticos, organizadoras de eventos, serviços de animação, parques temáticos, hotelaria e demais empreendimentos do setor;

$\mathrm{XV}$ - planejar, organizar e aplicar programas de qualidade dos produtos e empreendimentos turísticos, conforme normas estabelecidas pelos órgãos competentes;
XVI - emitir laudos e pareceres técnicos referentes à capacitação ou não de locais e estabelecimentos voltados ao atendimento do turismo receptivo, conforme normas estabelecidas pelos órgãos competentes;

XVII -lecionar em estabelecimentos de ensino técnico ou superior;

XVIII - coordenar e orientar levantamentos, estudos e pesquisas relativamente a instituições, empresas e estabelecimentos privados que atendam ao setor turístico. (LEI 12591/2012)

Basta ler a Lei para compreender que apenas o acadêmico que estudou as disciplinas oferecidas em curso superior de Turismo terá as competências e habilidades para atender os itens nesta citados.

É este profissional que deve atuar no mercado, com todos esses conhecimentos prévios e sempre disposto às mudanças que o mercado exige, se capacitando sempre, estudando idiomas, conhecendo novas culturas.

Portanto, qual o papel do professor em relação a este profissional que ele está formando? Para Ansarah (s/d):

A Educação na universidade de hoje deve preparar as novas gerações para a integração consciente e crítica em uma sociedade dinâmica e globalizada e os professores deixam de ser detentores e transmissores do "saber", passando a ter como função principal a preparação dos alunos para a apropriação crítica desse "saber". (ANSARAH, s/d, p.1-2)

A hospitalidade, tão aclamada pelos estrangeiros, deve permear todos os setores do turismo, sem amadorismo, como presenciei em algumas viagens e ouço depoimentos de outros professores e alunos que, por estarem no setor, ficam indignados.

Camargo (2005) afirma que "pessoas que viajam necessitam de acolhimento, envolvimento, e a hospitalidade torna-se um tema caro à economia moderna", portanto, devemos estudar e praticá-la com profissionalismo. 


\section{Conclusão}

Este trabalho, como já explanado, surgiu após uma oportunidade de palestrar no Equador. Lá, pude conversar com acadêmicos daquele país, do México, Costa Rica, Nicarágua, Cuba, Espanha, Colômbia e Brasil. À exceção do Equador que está investindo muito no setor, todos sentem a necessidade de melhorar e valorizar a área.

É preciso valorizar mais o profissional que investe em estudos, cursos, capacitações seja no âmbito acadêmico ou no trade turístico.

Muito se fala e pouco se faz no setor turístico. Talvez por arrogância, acredita-se que o Brasil é um país $100 \%$ turístico e, portanto, não é necessário investir na área. $\mathrm{O}$ setor público não dá a devida atenção ao setor. As IES por sua vez, em sua maioria não investem em laboratórios específicos do curso, optando pela economia, não proporcionando ao aluno a vivência prática.

Não é possível imaginar um futuro profissional do trade turístico que nunca utilizou dos modais para suas viagens, nunca se hospedou em um meio de hospedagem, nunca fez uso dos serviços de uma operadora de turismo, ou fez visita técnica. Qual a sua segurança ao sair para o mercado de trabalho? Nenhuma. Por isso, muitos, ao concluírem o curso não se aventuram nesse setor, com o agravante que os salários não são nada atrativos. Uma opção, seria o empreendedorismo. Mas, como, se não se sentem preparados?

Por isso, a importância de uma valorização desse profissional, para que ele se sinta atraído em atuar na área e se qualificar permanentemente.

Apenas um profissional que conheça muito bem fatores como segurança, legislação, hospitalidade, planejamento turístico enfim, toda a complexidade do turismo, pode receber bem os turistas, promover um bom trabalho, proporcionar uma estadia adequada. Este profissional tem argumentos, oferece tranquilidade. E este profissional é formado e capacitado por profissionais que atuam na área, que tenham aderência às disciplinas ministradas, que são compromissados, competentes e que esteja em sala de aula por amor e dedicação e não como uma fonte extra de renda.
O profissional de turismo deve estar ciente que, permanentemente deve conjugar três verbos para ser um diferencial no mercado: servir, encantar e surpreender.

\section{Referências bibliográficas}

Almeida, M. I. de. 2012 1. ed. Formação do professor do Ensino Superior: desafios e políticas institucionais. São Paulo: Cortez.

Alves, D. T. (2012) DILMA RECONHECE PROFISSÃO DE TURISMÓLOGO COM VETOS. São Paulo: Panrotas. Recuperado de <http://www.panrotas.com.br/noticia-turismo/politica/dilma-regulamenta-profissao-de-turismologo--com-vetos_74877.html>

Ansarah, Dra. Marilia Gomes dos Reis. (S/D) CURSO SUPERIOR DE TURISMO: A RELAÇÃO PROFESSOR ALUNO NA CONSTRUÇÃO DO CONHECIMENTO. Caxias do Sul: Universidade Caxias do Sul. Recuperado de <http:// www.ucs.br/site/midia/arquivos/gt13-curso-superior-deturismo.pdf $>$

Camargo, L. 2005. 2. ed. Hospitalidade. São Paulo: Aleph.

Cardoso, F. H. (1996) LEI DE DIRETRIZES E BASES DA EDUCAÇÃO NACIONAL. LEI N 9394 DE 20 DE NOVEMBRO DE 1996. Brasília: Presidência da República. Recuperado de <http://www.planalto.gov.br/ccivil_03/ leis/19394.htm>

Guimaraes, A. S.; Borges, M. P. e. 2008 1. ed. e-turismo: internet e negócios do turismo. São Paulo: Cengage Learning.

Hilton, L. (2014) 8 HÁBITOS E COSTUMES DOS BRASILEIROS QUE DEVERIAM SER EXPORTADOS, NA OPINIÃO DOS GRINGOS. São Paulo : R7. Recuperado de <http://www.tudointeressante.com.br/2014/07/8-habitose-costumes-brasileiros-quedeveriam-ser-exportados-na-opiniao-dos-gringos.html>

Mesquita, B. N.; Silva, J. T. M.; Ribeiro, A. L. (2009) O PAPEL DO PROFESSOR NA FORMAÇÃO DO BACHAREL EM TURISMO: UM ESTUDO DE CASO. Belo Horizonte: Educação em Foco. Recuperado de $<$ http://www. uemg.br/openjournal/index.php/educacaoemfoco/article/ view/83/118>

Molina, Sergio. 2013 2. ed. O Pós-Turismo. São Paulo: Aleph.

Rousseff, D. (2012) LEI No 12591 DE 18 DE JANEIRO DE 2012. Brasília: Presidência da República. Recuperado de $<$ http:// www.planalto.gov.br/ccivil_03/_ato2011-2014/2012/lei/ 112591.htm> 
Santana, A. L. (2009) CONCIERGE. São Paulo: Infoescola. Recuperado de <http://www.infoescola.com/profissoes/ concierge/>

Souza, A.; Saad, M. (2015) ECONOMIA DA EXPERIÊNCIA - TURISMO NOS DIAS ATUAIS. Brasília: Ministério do Turismo. Recuperado de <http://www.turismo. gov.br/turismo/programas_acoes_BACKUP_nao_apagar/programas_acoes/regionalizacao_turismo/economia_experiencia.html>

(s/a) (2013) PROGRAMA DE REGIONALIZAÇÃO DE TURISMO DIRETRIZES. Brasília: Ministério do Turismo. Recuperado de <http://www.turismo.gov.br/ export/sites/default/turismo/o_ministerio/publicacoes/ downloads_publicacoes/plano_nacional_2013.pdf> (s/a) (2015) ESTUDOS DA COMPETITIVIDADE DO TURISMO BRASILEIRO. Brasília: Ministério do Turismo Recuperado de <http://www.turismo.gov.br/ export/sites/default/turismo/o_ministerio/publicacoes/ downloads_publicacoes/TURISMO_COMO_INSTRUMENTO_DE_DESENVOLVIMENTO_REGIONAL_ESTUDO_DE_ARRANJOS_PRODUTIVOS LOCAIS_xAPLSx_NO_SETOR_DE_TURISMO. pdf $>$

(s/a) (2015) INSTITUIÇÕES DE EDUCAÇÃO SUPERIOR E CURSOS

CADASTRADOS. Brasília: Ministério da Educação. Recuperado de $<$ http://emec.mec.gov.br/> 
